\title{
Coronary artery bypass grafting in young patients - insights into a distinct entity
}

\author{
Felix Fleissner*, Gregor Warnecke, Serghei Cebotari, Saad Rustum, Axel Haverich and Issam Ismail
}

\begin{abstract}
Objectives: Coronary artery bypass grafting (CABG) is the 'Gold Standard' for patients with multiple vessel coronary artery disease (CAD). Younger patients presenting with coronary artery disease requiring surgery may represent a distinct subgroup with the main goal for coronary revascularization being long term patency of the performed grafts to improve outcome.

Methods: Between January 2010 and August 2013, 126 patients below the age of 50 years underwent CABG for CAD in our hospital. We retrospectively analyzed the perioperative data and evaluated patients' outcome.

Results: In 25\% of the patients CABG was performed as an emergency procedure for STEMI Or NSTEMI within 36 hours. Another $27 \%$ of the patients were operated urgently for unstable angina or myocardial infarction within the last weeks and only $48 \%$ of the patients were purely elective cases. We performed only venous bypass grafts in $12 \%$, total arterial revascularisation in 52\% of all cases and combined venous and arterial revascularization in $43 \%$. Six patients needed cardiac support using an extracorporeal membrane oxygenation (Mortality $n=1$ out of 6 ) and 17 patients received an intraaortic ballon pump perioperativly. Patients received $2.8 \pm 1$ bypass grafts overall. Overall in-hospital mortality in this cohort was low with $1 \%(n=1)$.

Conclusions: In conclusion, the majority of the young patients below the age of 50 years present urgently for operative revascularization. Besides the potential advances regarding long term patency using total arterial revascularization, only about half of the young patients are feasible for this approach. Overall early outcome in this group is excellent with mortality below one percent.
\end{abstract}

Keywords: CABG, Arterial grafts, Extracorporeal life support (ECLS), Myocardial ischemia, Ischemic cardiomyopathy

\section{Background}

Coronary artery bypass grafting (CABG) remains the Gold standard for excessive coronary artery disease involving three vessels or the left main stem [1]. CABG is more durable than percutaneous coronary intervention, especially when using arterial grafts only [2-4]. There is abundant literature regarding risks of elderly patients undergoing cardiac surgery [5-7]. However, reports about younger patients undergoing CABG are sparse. D'Errigo et al. recently reported the multicenter data concerning patients below 50 years of age receiving CABG with a mortality rate of $0.9 \%$ overall [8]. However, no details about the used grafts were given in that study. A low postoperative mortality rate has also been reported

\footnotetext{
* Correspondence: Fleissner.Felix@mh-hannover.de

Division of Cardiac, Thoracic, Transplantation and Vascular Surgery, Hannover Medical School, Hannover, Germany
}

(c) 2015 Fleissner et al.; licensee BioMed Central. This is an Open Access article distributed under the terms of the Creative Commons Attribution License (http://creativecommons.org/licenses/by/4.0), which permits unrestricted use, distribution, and reproduction in any medium, provided the original work is properly credited. The Creative Commons Public Domain Dedication waiver (http://creativecommons.org/publicdomain/zero/1.0/) applies to the data made available in this article, unless otherwise stated. by Khawaja et al. [9] in patients aged $<50$ years treated by percutaneous coronary intervention $(0.86 \%)$. However, percutaneous coronary interventions were performed in $41 \%$ of cases in patients with single vessel coronary artery disease, which is significantly different from surgical series [8].

Patients who would benefit most from prolonged patency of total artery revascularization are the young patients. In this study we therefore sought to further evaluate patients under the age of 50 years receiving coronary artery bypass grafting.

\section{Methods}

We retrospectively analysed all consecutive patients below the age of 50 years receiving $C A B G$ at our clinic from January 2010 until August 2013. The Ethics Committee of Hanover Medical School approved this study. Informed 
consent was obtained from the patient for the publication of this report.

\section{Operative technique}

A full median sternotomy was performed (except one patient receiving an upper hemisternotomy due to a high grade stenosis of the right coronary artery of anomalous origin). We used cardiopulmonary support in most cases $(\mathrm{n}=125)$, except for the patient receiving the upper hemisternotomy.

\section{Total arterial revascularization (TAR)}

After a full median sternotomy the LITA was harvested in no touch technique with minimal trauma as pedicled graft and treated with papaverine solution prior to use. RA was harvested from the non-dominant arm. We performed duplex sonography to assure open palmar arches. The T-graft was performed prior to initiating CPB between the RA and the LITA using an 8-0 prolene suture. $\mathrm{CBP}$ was initiated after completion of the $\mathrm{T}$ graft.

\section{Combined venous and arterial revascularization}

We usually used the LITA and the saphenous vein as grafts. The LITA was most frequently anastomosed to the LAD or D1, whereas the saphenous vein was used for up to three sequential anastomoses. The venous only revascularization was achieved using the saphenous vein as aortocoronary bypass anastomosed to the acending aorta as standardized.

$\mathrm{CPB}$ was instituted with cannulation of the ascending aorta and a single two-stage right atrial cannulation. Standard bypass management included membrane oxygenators, arterial line filters, and non-pulsatile flow (or pulsatile flow for patients kidney failure) with a mean arterial pressure greater than $50 \mathrm{~mm} \mathrm{Hg}$. The myocardium was protected by using intermittent antegrade cold blood cardioplegia or crystalloid solution. Anticoagulation was achieved using $300 \mathrm{U} / \mathrm{kg}$ of heparin. If required, heparin was supplemented to maintain the activated clotting time above $450 \mathrm{~s}$ and was fully reversed with protamine at the end of the procedure. Patients received intravenous nitroglycerin infusions for the first $24 \mathrm{~h}$ if feasible. Inotropic agents were chosen by the haemodynamic state. Other routine medications included daily aspirin (300mg Aspirin i.v. 6 hour postoperatively unless bleeding occurred, 100mg Aspirin p.o. the first postoperative day) and resumption of cholesterol-lowering agents and $\beta$-blockers unless contraindicated beginning during the early postoperative course.

\section{Statistical analysis}

Statistical analysis was performed using SPSS 22 package (SPSS Inc, Chicago, Il, USA). The data were shown as mean \pm SD. Comparison of groups was performed using unpaired t-test or ANOVA with statistical significance assumed for $\mathrm{p}$ values $<0.05$.

\section{Results}

\section{Patients}

A total of 126 CABG cases in patients below the age of 50 years were performed. Twenty five percent $(n=30)$ of the operations were emergencies, Twenty seven percent $(\mathrm{n}=35)$ of the patients were operated urgently and only $48 \%(n=61)$ of the patients were elective cases. 52 patients recently had a myocardial infarction ( $<30$ days) of which 18 patients presented with myocardial infarction under 12 hours prior to the operation.

Median age was 46.98 (range from: $24-49), 81 \%(n=102)$ of the patients were male. Patients usually presented with multiple risk factors. Arterial hypertension was present in $77 \%$, nicotine abuse in $79 \%$ and hyperlipidaemia in $71 \%$ of patients. Obesity was present in $34 \%$ of cases, diabetes mellitus in $25 \%$ of cases and a familial pre-disposition was reported in only $20 \%$ of cases. The overall preoperative left ventricular ejection fraction (LV-EF) was $55.5 \%( \pm 13.8 \%)$. However, $12 \%$ of patients presented with a poor LV-EF below $35 \%$. Only two patients were cardiac re-dos (one AVR and one CABG). Nine patients recently underwent CPR in the pre-operative course due to ventricular fibrillation. 36 Patients had already undergone PTCA/Stent implantation before they were admitted to cardiac surgery.

Of these 36 patients who received an intervention prior to CABG, 3 patients presented with iatrogenic dissections in the target vessels and were subsequently referred to CABG, 4 patients had undergone an unsuccessful PCI attempt in one or two target vessels prior to referral to operative revascularization. 10 patients presented with in-stent re-(re) stenosis in stented vessels. Only one patient received a PCI (without stent implantation) of the culprit lesion (RPLA) directly prior to surgery as a bridging therapy to surgical revascularization in acute myocardial infarction (STEMI). One patient was reanimated extrahospitally and received a lysis therapy. The patient received a coronary angiogram after admission to the hospital which showed a 3 vessel disease. Another patient with an iatrogenic dissection of the LAD received ReoPro directly prior to operation as a rescue attempt.

$66 \%(n=83)$ of patients were symptomatic prior to the operation (NSTEMI, STEMI and unstable angina).

Six patients presented with severe mitral valve regurgitation du to ischemic papillary muscle rupture. 12 Patients had renal insufficiency preoperatively, of those 3 patients were on dialysis. For further pre-operative details, please refer to Table 1.

Operation, cardiopulmonary bypass and clamp times were $203.96 \pm 58.51 \mathrm{~min} 88.70 \pm 39.97 \mathrm{~min}$ and $49.95 \pm$ $22.63 \mathrm{~min}$, respectively. ICU stay and overall hospital 
Table 1 Patient's characteristics

\begin{tabular}{|c|c|}
\hline Patient's characteristics: & \\
\hline Age, years & 46.98 (range from: 24-49) \\
\hline Sex, male (\%) & $102(81)$ \\
\hline $\begin{array}{l}\text { Left ventricular ejection fraction } \\
\text { in } \%( \pm \mathrm{SD})\end{array}$ & $55.5( \pm 13.8)$ \\
\hline Poor LV-EF (35\% or below) & $15(12)$ \\
\hline Creatinine $( \pm S D)$ & $85.6( \pm 66.9)$ \\
\hline CK U/I ( \pm SD) & $375.9( \pm 1072)$ \\
\hline CK-MB U/I ( \pm SD) & $45.4( \pm 96.1)$ \\
\hline Pre-op renal insufficiancy (\%) & $12(10)$ \\
\hline Pre-op dialysis (\%) & $3(2)$ \\
\hline Arterial hypertension (\%) & $97(77)$ \\
\hline Nicotine abuse (\%) & $99(79)$ \\
\hline Hyperlipidaemia (\%) & $89(71)$ \\
\hline Diabetes mellitus (\%) & $25(20)$ \\
\hline Obesity (\%) & $43(34)$ \\
\hline Emergency (\%) & $30(25)$ \\
\hline Urgent (\%) & $35(27)$ \\
\hline Elective (\%) & $61(48)$ \\
\hline $\begin{array}{l}\text { Non-ST-elevation acute coronary } \\
\text { syndrome (\%) }\end{array}$ & $25(20)$ \\
\hline Recent STEMI (\%) & $25(20)$ \\
\hline Unstable angina (\%) & $33(26)$ \\
\hline Stable angina (\%) & $43(34)$ \\
\hline Previous PTCA/Stent (\%) & $36(28)$ \\
\hline $\begin{array}{l}\text { Unsuccessful previous PTCA/Stent } \\
\text { attempt (\%) }\end{array}$ & $3(2)$ \\
\hline IABP & $17(14)$ \\
\hline ECLS & $6(5)$ \\
\hline Cardiac Re-do & $2(2)$ \\
\hline
\end{tabular}

Continuous variables are presented with the standard deviation or median with range (age), categoric variables are presented as number (\%).

LV-EF (Left-ventricular ejection fraction), CK (creatinine kinase), CK-MB (muscle-brain creatinine kinase), STEMI (ST-elevation myocardial infarction), IABP(intraaortic ballon pump), ECLS (Extracorporal Life Support System), PTCA (percutaneous transluminal coronary angioplasty).

stay were $2.23 \pm 3.54$ days and $8.64 \pm 4.57$ days respectively (See Table 2). In-hospital and 30 day mortality was $0.9 \%(\mathrm{n}=1)$. Six patients needed Extracorporal Life Support System (ECLS) (See Table 3) and 17 patients received peri-operative intraaortic ballon pump (IABP) support. One patient died during postoperative course. This patient presented in cardiogenic shock due to STEMI, was switched from IABP support to ECLS support and died during post-operative course despite all efforts in multi-organ failure. Retrospectively, this patient might have benefited from initial ECLS support instead of IABP support. The other five patients could be weaned successfully from ECLS support. Concomitant procedures included mitral valve repair or replacement in
Table 2 Operative data

\begin{tabular}{ll}
\hline Operative data: & \\
\hline Operation time min $( \pm$ SD) & $203.96( \pm 58.51)$ \\
Cardiopulmonary bypass times min $( \pm$ SD) & $88.71( \pm 39.97)$ \\
Clamp times min $( \pm$ SD) & $45.95( \pm 22.63)$ \\
Of-pump procedures & $1(1)$ \\
Venous bypass grafts (exclusivly) & $15(12)$ \\
Total arterial revascularization & $66(52)$ \\
Arterial and venous revascularization & $43(34)$ \\
Number of performed bypass grafts $n( \pm$ SD) & $2.87( \pm 0.92)$ \\
Concomittant procedures & \\
Mitral valve repair & 3 \\
Mitral valve replacement & 3 \\
Aortic valve replacement & 1 \\
DOR Plasty & 3 \\
Carotid TEA & 1 \\
\hline Continuous variables are presented with the standard deviation; categoric \\
variables are presented as number $(\%)$. Carotid TEA (thromboendarterectomy).
\end{tabular}

six patients. One patient received an aortic valve replacement due to severe aortic insufficiency and one patient received a carotid endarterectomy. Three patients received a DOR plasty due to left ventricular aneurysms.

The left internal thoracic artery (LITA) was used in 111 cases $(88 \%)$ and either anastomosed to the LAD, LAD and $\mathrm{D} 1$, or to the RIM. The right internal thoracic artery (RITA) was used in 8 cases (6\%). The radial artery (RA) as a T-graft was used in 51 cases and as a free graft in two cases. In total, the RA was used in 53 cases (42\%).

In case of a total arterial revascularisation, combined venous and arterial revascularisation and venous revascularisation only, $2.6( \pm 0.89), 3.19( \pm 0.93)$ and $2.75( \pm 1.39)$ bypass grafts were anastomosed, respectively.

We performed venous bypass grafts in $12 \%(n=15)$, total arterial revascularisation (using mainly the left internal thoracic artery with the radial artery as T-graft) in $52 \%(\mathrm{n}=62)$ of all cases and combined venous and arterial revascularization in $43 \%(n=34)$.

Total arterial revascularisation was performed in 68\% of elective cases. Urgent cases received total arterial revascularisation in $57 \%$ of cases. However, the emergent cases were suitable for total arterial revascularisation in $17 \%$ of cases. Accordingly, combined venous and arterial revascularisations in elective, urgent and emergency operations were $26 \%, 37 \%$ and $50 \%$, respectively (See also Figure 1).

Postoperative course included two patients with a pulmonary embolism and one patient with a peri-operative stroke. Incidentally, the patient who suffered from stroke intra-operatively had an undiagnosed atrial septum defect (ASD), despite pre-operative echocardiography, and received an ASD closure during a later hospital stay after 


\section{Table 3 ECLS subgroup analysis}

\section{Patient Presentation}

NSTEMI, CA: Bifurcation stenosis of LAD/D1

2 Present to referring hospital with angina,

CA: RCA 100\%, CX: procimal 90\%, LAD; 100\%

unsuccessful attempt for PTCA/Stentimplant

of the CX with iatrogenic dissection, rescue

attempt with ReoPro, CPR during postoperative

to primary hospital

3 STEMI, CA: LAD 100\% proximal, CX, PLA 1 90\%, RCA $100 \%$, Patient in cardiogenic shock with unstable hameodynamic under catecholamines,

immediate referral to OR

$4 \quad$ Unstable angina, CA: LAD 90\%, Cx 100\%, RCA $100 \%$, cardiac decompensation with periphera oedema and septic ulcers, multiple sclerosis, severe obesity

5 presentation with beginning cardiac decompensation and respiratory insufficiency, CA: LAD 100\%, CX 90, RCA 90\%, ECLS support in reffering hospital prior to transport, Echo: LV-EF 45\%, MI III (rupture of posteromedian papillary muscle)

$6 \quad$ Angina and Dyspnoea in referring hospital, CA: LAD 40\%, PLA 2 90\%, RIVP 70\%, MI III

\section{Indication for ECLS}

\section{ECLS support Surgery}

Postoperative course

\section{Outcome}

difficult weaning from CPB d0-d2 LIMA-LAD,-D1

ECMO explanation D3, uneventful

V-EF at discharge $50 \%$

difficult weaning from CPB d0-d9 ACVB-LAD, ACVB-

under running IABP, ECLS

dialysis during postoperative course ECLS support), LV-EF prior with tracheotomy, removed POD 23,

to discharge: $50 \%$

Re-Thoracotomy POD 1, POD 12 due to

haematothorax with pericardial tamponade

cardiogenic shock, difficult d0-d12 LIMA-LAD, ACVB- dialysis during postoperative course, weaning from CPB under RIVP-PLA dialysis during postc,
recovery day 14,

LIMA-LAD-D1, radial Dialysis during postoperative course, artery PLA-RIVP compartment syndrome left lower leg, (septic ulcers, no vein re-thoracotomy due to tamponade, grafts available)

weaning from CPB under IABP support

cardiogenic shock $d-1-d 4$ MVR (SJM, 29 mm) ACVB-LAD, ACVBPLA1-RIVP septic shock

Dialysis during postoperative course, recovered POD 5, short CPR on POD 5, CD implantation POD 30

difficult weaning from CPB, ECLS intraoperativly d0-d8

$$
\text { MVR (anuloplasty }
$$$$
\text { PLA-RIVP }
$$

Clinical presentation, performed surgery, postoperative course and outcome of the six patients requiring ECLS. ECLS (Extracorporal Life Support System) NSTEMI (Non-ST-Elevated Myocardial Infarction), STEMI (ST-elevation myocardial infarction), MI (mitral valve insufficiency), IABP (intraaortic ballon pump), CPB (Cardiopulmonary bypass) POD (Postoperative day), LV-EF (Lef-ventricular ejection fraction), PVL (paravalvular leakage). 


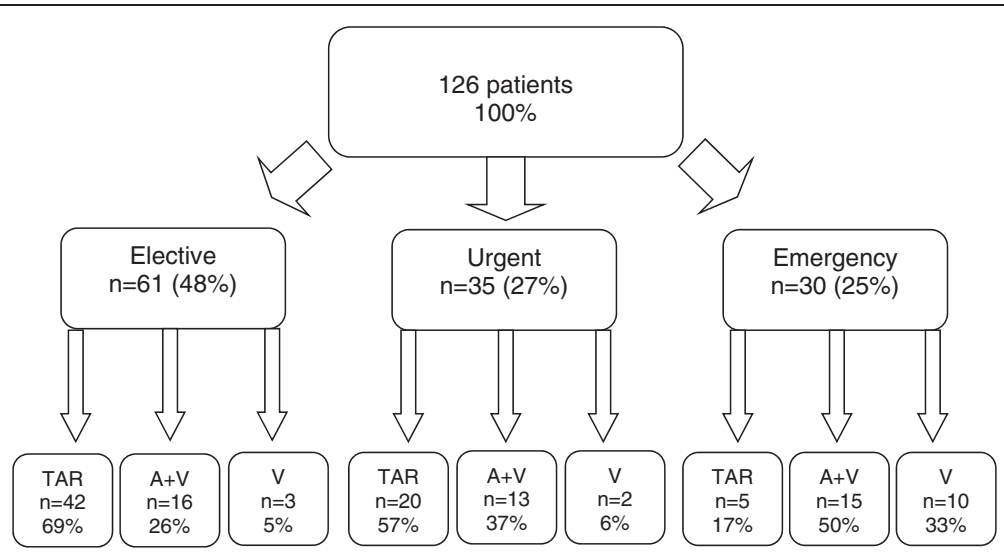

Figure 1 Flow chart of the 126 pts. receiving coronary artery bypass grafting. TAR: total artery revascularisation, $A+V$ : combined venous and arterial revascularisation, $\mathrm{V}$ : venous grafts only.

she recovered from the initial operation. 10 patients needed prolonged ventilatory support $(>48 \mathrm{~h})$ and six patients developed a transient kidney insufficiency postoperatively (See Table 4).

Three patients needed a revision of their bypass grafts after suffering from postoperative myocardial infarction, and three patients needed revision due to symptomatic bleeding with either a haematothorax $(n=2)$ or pericardial tamponade $(n=1)$. One of the patients with postoperative bleeding had undergone a rescue attempt using Abciximab (ReoPro) in the cath lab due to an iatrogenic dissection of the LAD directly prior to operation. Seven patients were re-administered after recovery for removal of the sternal cerclages, all due to pain during movement.

\section{Discussion}

Despite all advances in prevention and diagnostics, as well as general awareness for cardiovascular disease in the elderly, our patient collective with young patients below 50 years of age often present in urgent or

\section{Table 4 Postoperative course}

\begin{tabular}{ll}
\hline Re-Thoracotomy & $6(5)$ \\
Bleeding & $3(2)$ \\
Respiratory insufficiancy & $10(8)$ \\
Postoperative renal insufficiancy & $6(5)$ \\
Stroke & $1(1)$ \\
Postop coronary angiogram (unplanned) & $3(2)$ \\
Secondary thoracic operations & $9(7)$ \\
Post-op left ventricular ejection fraction in \% ( \pm SD) & $56.83( \pm 12.13)$ \\
In hospital death & $1(1)$ \\
Revision of bypass grafts & $3(2)$ \\
\hline
\end{tabular}

Continuous variables are presented with the standard deviation; categoric variables are presented as number (\%). emergency settings. We have to assume that especially in these young patients with multiple risk factors; diagnosis of a coronary artery disease is delayed because of inadequate awareness. Clinical presentation of our patients collective was rather heterogeonus which makes a direct, propensity matched comparison very difficult. Especially the high frequency of extra hospital reanimated patients and patients with iatrogenic complications during PCI, makes a comparison to previous published studies for CABG difficult.

Although the recent long-term results from the SYNTAX [1], ASCERT [9], and FREEDOM [10] trials showed significantly better survival rates after CABG than after PCI, CABG rates are declining over the past years, while PCI rates increase accordingly [11]. Nonetheless, CABG remains the Gold Standard for patients with coronary artery disease including those with diabetes and/or complex left main or three-vessel disease [1,9].

The technique of CABG has not changed significantly over the past years. However, the use of bypass material remains under intense discussion. The use of one internal thoracic artery as graft, most often the LITA anastomosed to the LAD combined with venous conduits represents the standard therapy for patients undergoing CABG [12].

Failure rates of up to $12 \%$ of saphenous vein grafts within the first week after operation have been described. Therefore alternative grafts such as bilateral internal thoracic artery or radial artery grafts are more frequently used.

The long-term results from recent trials suggest favorable radial artery graft patency rates over saphenous vein grafts $[13,14]$. Accordingly, several large observational studies have confirmed excellent graft patency and have reported superior long-term survival rates, [15] also after applying propensity matching $[4,16]$ for patients receiving the radial artery as bypass grafts. However, concerns regarding vessel spasm, graft atherosclerosis, and unfavorable results from a number of studies exist. We do 
however; believe in the use of the radial artery as our standard graft in patients with no contraindications against this approach.

While these young patients would benefit most from a total arterial revascularization given its superior long term patency rates [4,13-16], this approach is frequently not possible. In our series, $57 \%$ of urgent and $17 \%$ of emergency cases received a TAR in the subgroup analysis.

In our case series, $12 \%$ of patients present with a left ventricular ejection fraction of 35\% or lower. This underlines

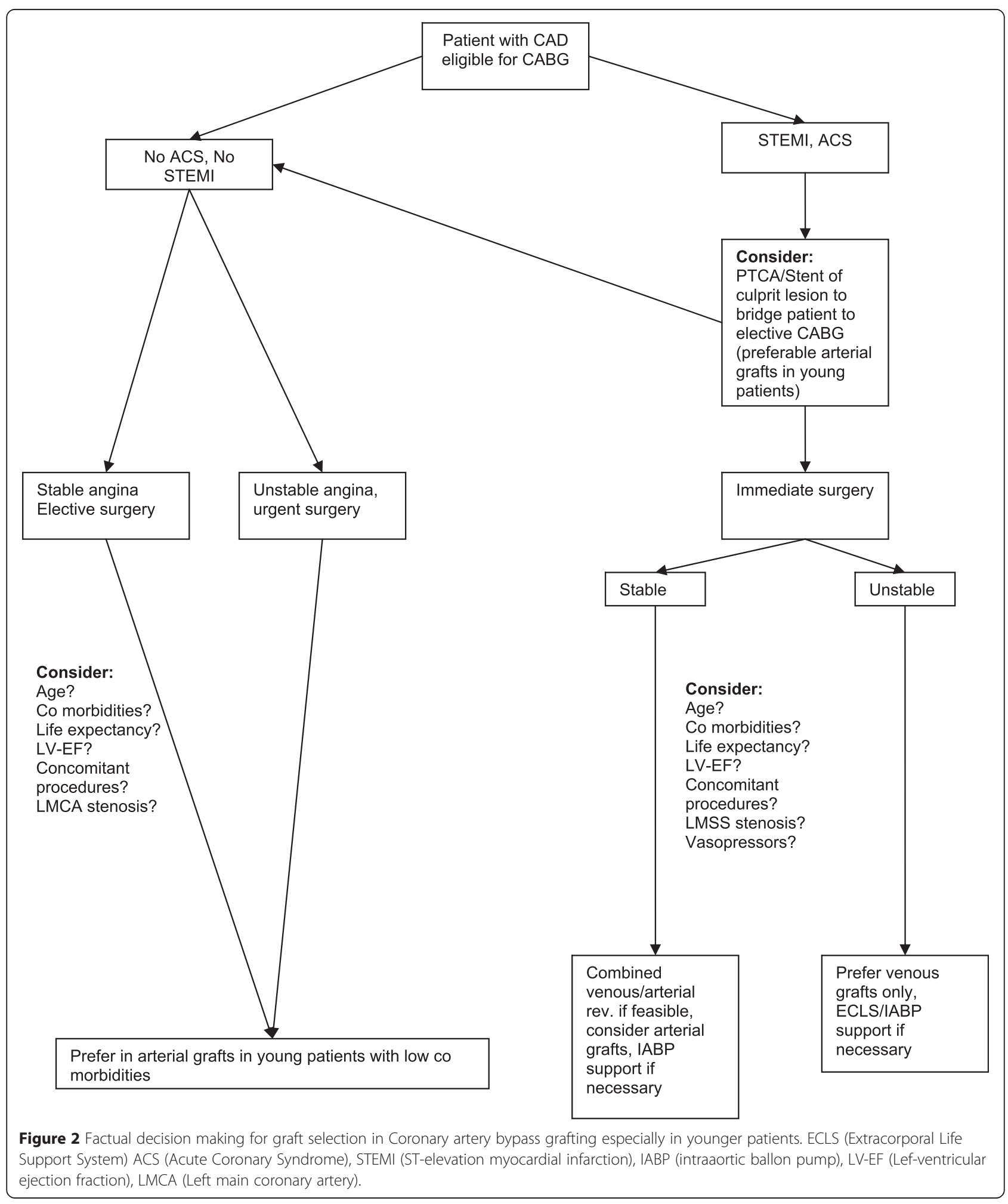


the fact that especially this patient collective is administered to the hospital in a later stage of their disease.

However, the possible long-term advantage of a TAR is diminished by the fact that the life expectancy of these ill patients is severely diminished. Although, the options for a patient requiring CABG are small (TAR, venous and arterial revascularization, venous revascularization only) the decision making process is rather complex (see Figure 2). In general we agree that absolute contraindications for a TAR are: cardiogenic shock, expected high doses of postoperative catecholamines and a life expectancy of less then 10 years. Graft availability is sometimes limited, too. Especially patients requiring dialysis prior to operation or patients that will require dialysis in the future might, the use of the LITA or RITA is forbidden for sake a cimino fistula. Chronic obstructive lung disease, if severe, might lead to the use of venous grafts only to keep the pleura closed. None the less, we are less concerned about the age of the patient since the use of radial artery grafts for revascularization not only leads to better graft patency rates, however graft harvesting site related complications are also quite rare, and less frequent then with the use of saphenous vein grafts.

Emergency operations, as well as an impaired left ventricular function (below 35\% LV-EF) are relative contraindications for a total arterial revascularization. Urgent cases with stable haemodynamics might or might not receive TAR. The usage of TAR in cases of left main coronary artery stenosis (LMCA) is currently under discussion. However, LMCA stenosis is only a relative contraindication for TAR at our department and underlies the surgeon's discretion.

We also found these patients to be prone for complications, and re-operation rates were relatively high, especially those for removal of sternal cerclages. This could be in fact due to a more active lifestyle of this patient collective. None of these were secondary operations were due to sternal wound infections. In fact, the wound complication rate in this collective was very low. This might be due to the low rate of diabetics, a disease primarily of the elderly patient.

In general our low postoperative mortality rate is similar to that reported by Khawaja et al. [17]. Available data about the postoperative morbidity of young CABG patients report $94 \%$ of patients aged $<50$ years undergoing CABG recovering without any major events and $96 \%$ of patients being discharged to home [8].

\section{Conclusions}

Findings prove that surgical revascularization for coronary artery disease can be performed with very low mortality in young patients. However, presentation of patients with high rates of emergency and urgent cases often hinder the favourable approach of total arterial revascularization.

\section{Limitations}

A limitation of this study is the lack of data on long-term outcome. Comparative studies evaluating the immediate and late outcome studies are needed to further refine the strategy of revascularization in young patients receiving CABG.

\section{Competing interests}

The authors declare that they have no competing interests.

\section{Authors' contributions}

II, AH, SC, GW, FF designed the study and drafted the manuscript. FF and SR collected the data and performed the statistical analysis. All authors read and aproved the final manuscript.

Received: 17 November 2014 Accepted: 17 April 2015

Published online: 01 May 2015

\section{References}

1. Mohr FW, Morice MC, Kappetein AP, Feldman TE, Ståhle E, Colombo A, et al. Coronary artery bypass graft surgery versus percutaneous coronary intervention in patients with three-vessel disease and left main coronary disease: 5-year follow-up of the randomised, clinical SYNTAX trial. Lancet. 2013;381(9867):629-38.

2. Kappetein AP, Feldman TE, Mack MJ, Morice MC, Holmes DR, Ståhle E, et al. Comparison of coronary bypass surgery with drug-eluting stenting for the treatment of left main and/or three-vessel disease: 3-Year follow-up of the SYNTAX trial. Eur Heart J. 2011;32:2125-34.

3. D'Errigo P, Seccareccia F, Barone AP, Fusco D, Rosato S, Maraschini A, et al. Effectiveness of invasive reperfusion therapy and standard medical treatment in AMI. Acta Cardiol. 2010;65:645-52.

4. Locker C, Schaff HV, Dearani JA, Joyce LD, Park SJ, Burkhart HM, et al. Multiple arterial grafts improve late survival of patients undergoing coronary artery bypass graft surgery: analysis of 8622 patients with multivessel disease. Circulation. 2012;126:1023-30.

5. Buth KJ, Gainer RA, Legare JF, Hirsch GM. The changing face of cardiac surgery: practice patterns and outcomes 2001-2010. Can J Cardiol. 2014;30(2):224-30.

6. Kurlansky P. Do octogenarians benefit from coronary artery bypass surgery: a question with a rapidly changing answer? Curr Opin Cardiol. 2012;27(6):611-9.

7. Vasques F, Lucenteforte E, Paone R, Mugelli A, Biancari F. Outcome of patients aged $\geq 80$ years undergoing combined aortic valve replacement and coronary artery bypass grafting: a systematic review and meta-analysis of 40 studies. Am Heart J. 2012;164(3):410-418.e1.

8. D'Errigo P, Biancari F, Maraschini A, Rosato S, Badoni G, Seccareccia F. Thirty-day mortality after coronary artery bypass surgery in patients aged $<50$ years: results of a multicenter study and meta-analysis of the literature. J Card Surg. 2013;28(3):207-11.

9. Weintraub WS, Grau-Sepulveda MV, Weiss JM, O’Brien SM, Peterson ED, Kolm $\mathrm{P}$, et al. Comparative effectiveness of revascularization strategies. N Engl J Med. 2012;366:1467-76.

10. Farkouh ME, Domanski M, Sleeper LA, Siami FS, Dangas G, Mack M, et al. Strategies for multivessel revascularization in patients with diabetes. N Engl J Med. 2012;367:2375-84.

11. Epstein AJ, Polsky D, Yang F, Yang L, Groeneveld PW. Coronary revascularization trends in the United States, 2001-2008. JAMA. 2011;305:1769-76.

12. Hayward PA, Buxton BF. Contemporary coronary graft patency: 5-year observational data from a randomized trial of conduits. Ann Thorac Surg. 2007;84:795-9.

13. Collins P, Webb CM, Chong CF, Moat NE. Radial Artery Versus Saphenous Vein Patency Trial Investigators. Radial artery versus saphenous vein patency randomized trial: five-year angiographic follow-up. Circulation. 2008;117:2859-64. 
14. Deb S, Cohen EA, Singh SK, Une D, Laupacis A, Fremes SERAPS. Investigators. Radial artery and saphenous vein patency more than 5 years after coronary artery bypass surgery: results from RAPS (Radial Artery Patency Study). J Am Coll Cardiol. 2012;60:28-35.

15. Schwann TA, Al-Shaar L, Engoren M, Habib RH. Late effects of radial artery vs. saphenous vein grafting for multivessel coronary bypass surgery in diabetics: a propensity-matched analysis. Eur J Cardiothorac Surg. doi:10.1093/ejcts/ezt061. Published online ahead of print 21 February 2013.

16. Zacharias A, Habib RH, Schwann TA, Riordan CJ, Durham SJ, Shah A. Improved survival with radial artery versus vein conduits in coronary bypass surgery with left internal thoracic artery to left anterior descending artery grafting. Circulation. 2004;109:1489-96.

17. Khawaja FJ, Rihal CS, Lennon RJ, Holmes DR, Prasad A. Temporal trends (over 30 years), clinical characteristics, outcome, and gender in patients_50 years of age having percutaneous coronary intervention. Am J Cardiol. 2011;107:668-74.

\section{Submit your next manuscript to BioMed Central and take full advantage of:}

- Convenient online submission

- Thorough peer review

- No space constraints or color figure charges

- Immediate publication on acceptance

- Inclusion in PubMed, CAS, Scopus and Google Scholar

- Research which is freely available for redistribution 